\title{
Electron-impact electronic-state excitation of para-benzoquinone
}

Cite as: J. Chem. Phys. 148, 124312 (2018); https://doi.org/10.1063/1.5023494

Submitted: 24 January 2018 . Accepted: 08 March 2018 . Published Online: 27 March 2018

D. B. Jones (D), R. F. da Costa, F. Kossoski (D), M. T. do N. Varella (D), M. H. F. Bettega (D), F. Ferreira da Silva, P. Limão-Vieira (D), G. García, M. A. P. Lima (D), R. D. White, and M. J. Brunger

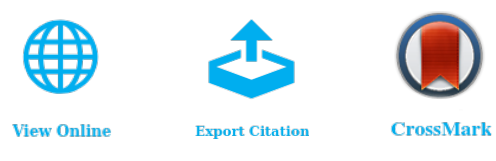

\section{ARTICLES YOU MAY BE INTERESTED IN}

Integral elastic, vibrational-excitation, electronic-state excitation, ionization, and total cross sections for electron scattering from para-benzoquinone

The Journal of Chemical Physics 148, 204305 (2018); https://doi.org/10.1063/1.5028298

An ab initio investigation for elastic and electronically inelastic electron scattering from para-benzoquinone

The Journal of Chemical Physics 149, 174308 (2018); https://doi.org/10.1063/1.5050622

Elastic scattering and vibrational excitation for electron impact on para-benzoquinone

The Journal of Chemical Physics 147, 244304 (2017); https://doi.org/10.1063/1.5010831
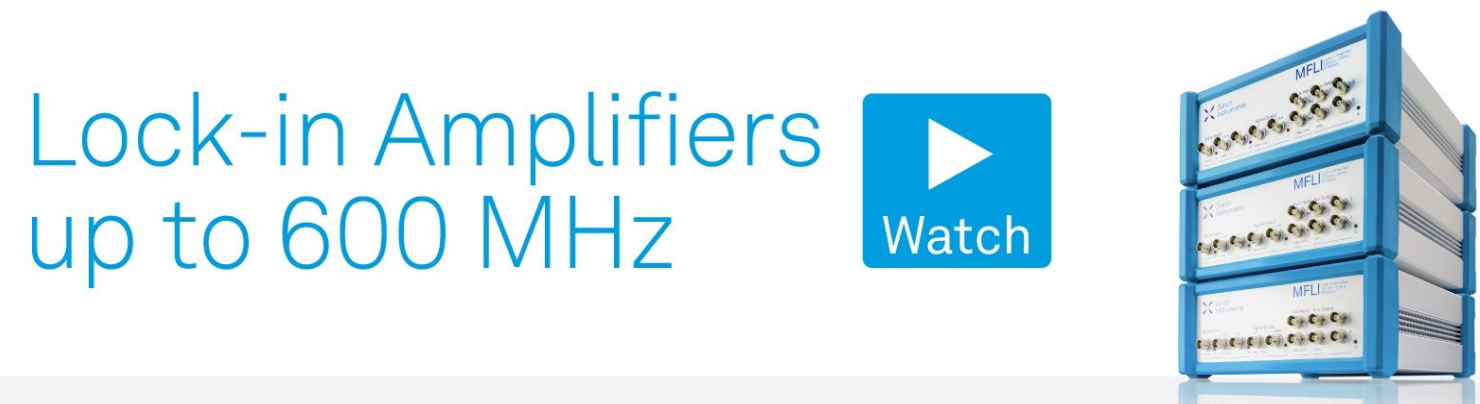

J. Chem. Phys. 148, 124312 (2018); https://doi.org/10.1063/1.5023494 


\title{
Electron-impact electronic-state excitation of para-benzoquinone
}

\author{
D. B. Jones, ${ }^{1, a)}$ R. F. da Costa, ${ }^{2,3}$ F. Kossoski, ${ }^{2}$ M. T. do N. Varella, ${ }^{4}$ M. H. F. Bettega, ${ }^{5}$ \\ F. Ferreira da Silva, ${ }^{6}$ P. Limão-Vieira, ${ }^{6}$ G. García, ${ }^{7}$ M. A. P. Lima, ${ }^{2, a)}$ R. D. White, ${ }^{8}$ \\ and M. J. Brunger ${ }^{1}$ \\ ${ }^{1}$ College of Science and Engineering, Flinders University, GPO Box 2100, Adelaide, SA 5001, Australia \\ ${ }^{2}$ Instituto de Física "Gleb Wataghin," Universidade Estadual de Campinas, 13083-859 Campinas, \\ São Paulo, Brazil \\ ${ }^{3}$ Centro de Ciências Exatas, Departamento de Física, Universidade Federal do Espírito Santo, \\ 29075-910 Vitória, Espírito Santo, Brazil \\ ${ }^{4}$ Instituto de Física, Universidade de São Paulo, Rua do Matão 1731, 05508-090 São Paulo, São Paulo, Brazil \\ ${ }^{5}$ Departamento de Física, Universidade Federal do Paraná, CP 19044, 81531-990 Curitiba, Paraná, Brazil \\ ${ }^{6}$ Laboratório de Colisões Atómicas e Moleculares, CEFITEC, Departamento de Física, Faculdade de Ciências \\ e Tecnologia, Universidade NOVA de Lisboa, 2829-516 Caparica, Portugal \\ ${ }^{7}$ Instituto de Fisica Fundamental, CSIC, Serrano 113-bis, E-28006 Madrid, Spain \\ ${ }^{8}$ College of Science and Engineering, James Cook University, Townsville, Australia
}

(Received 24 January 2018; accepted 8 March 2018; published online 27 March 2018)

\begin{abstract}
Angle resolved electron energy loss spectra (EELS) for para-benzoquinone $\left(\mathrm{C}_{6} \mathrm{H}_{4} \mathrm{O}_{2}\right)$ have been recorded for incident electron energies of 20,30, and $40 \mathrm{eV}$. Measured differential cross sections (DCSs) for electronic band features, composed of a combination of energetically unresolved electronic states, are subsequently derived from those EELS. Where possible, the obtained DCSs are compared with those calculated using the Schwinger multichannel method with pseudopotentials. These calculations were performed using a minimum orbital basis single configuration interaction framework at the static exchange plus polarisation level. Here, quite reasonable agreement between the experimental cross sections and the theoretical cross sections for the summation of unresolved states was observed. Published by AIP Publishing. https://doi.org/10.1063/1.5023494
\end{abstract}

\section{INTRODUCTION}

Benzoquinones play an important role in biological systems, undergoing reversible reduction as a key mechanism within photosynthesis or cellular respiration. Quinone derivatives are therefore being explored as a low-cost, sustainable material that can be used in energy harvesting and storage devices. ${ }^{1,2}$ para-Benzoquinone (pBQ, $\mathrm{C}_{6} \mathrm{H}_{4} \mathrm{O}_{2}$ ) is the simplest quinone and therefore serves as the ideal prototypical structure for understanding the electronic properties and mechanisms of quinone chemistry. The spectroscopy of quinones has therefore attracted considerable attention over an extended period, with comprehensive reviews by Itoh $^{3}$ and more recently by Ómarsson and Ingólfsson. ${ }^{4}$ While the electronic-state spectroscopy is complicated by a large number of closely lying (in energy) states, photo-, chemi-, and electron-impact ionization $^{5-11}$ investigations have helped to clarify the ordering of orbitals in the neutral species and its cationic structure. The anion states of $\mathrm{pBQ}$ and quinone derivatives have also been heavily studied, particularly through dissociative and non-dissociative electron attachment and electron scattering resonances. ${ }^{12-14}$ The nature of these low-lying resonances has recently been investigated through an R-matrix calculation. ${ }^{15}$ We have also recently reported a high-resolution synchrotron

\footnotetext{
a)Authors to whom correspondence should be addressed: darryl.jones@ flinders.edu.au and maplima@ifi.unicamp.br
}

investigation (4.0-10.8 eV) into the excited electronic structure of $\mathrm{pBQ}$ that also included results from detailed quantum chemical computations. ${ }^{16}$

We have for some time now been investigating electron scattering differential cross sections (DCSs) for elastic, vibrational, and electronic-state excitations and ionization processes from large molecules that serve as prototypical moieties for those found in more complex biomolecular systems. In this context, we have considered tetrahydrofuran, ${ }^{17-19}$ tetrahydrofurfuryl alcohol, ${ }^{20-22}$ and pyrimidine ${ }^{23-27}$ as analogues to the DNA bases and backbone. We have also considered scattering from phenol ${ }^{28-31}$ and furfural, ${ }^{32-36}$ which are ideal molecular candidates for describing the complex biopolymers found in biomass or components of biofuels. Note that all of these data from our group were recently summarised in the review by Brunger. ${ }^{37}$ Our cross sections are then incorporated into transport simulations to describe radiation damage in tissue $^{38,39}$ or swarms of electrons that describe physical processes occurring in plasma-like environments. ${ }^{40-42}$ These computational simulations are important in extending dosimetry to the quantification of induced chemical processes within nanosized volumes and building predictive plasma models that can be used to optimise plasma-based technologies for medical therapies ${ }^{43,44}$ or novel chemical processing. ${ }^{45-50}$ The present investigation continues this rich vein of research, seeking to contribute to the cross section data base ${ }^{51}$ that will ultimately be employed to study the behaviour of electrons in pBQbased swarm measurements, similar to what we undertook in 
Ref. 52, and to also simulate charged-particle track behaviour $^{53}$ in $\mathrm{pBQ}$.

In the present manuscript, we report on experimental and theoretical differential cross sections for electron impact electronic-state excitation of para-benzoquinone, with the structure of the remainder of this paper being as follows. In Sec. II, we detail the experimental and theoretical methods employed in this study. Our results are presented and discussed in Sec. III, with our conclusions being finally summarised in Sec. IV.

\section{EXPERIMENTAL AND THEORETICAL METHODS}

Electron energy loss spectra (EELS) have been recorded on a high-resolution electron scattering spectrometer that has been described previously. ${ }^{54}$ A mono-energetic electron beam, with energy $E_{0}$, is crossed at right angles with a molecular beam of $\mathrm{pBQ}$. The mono-energetic electron beam typically had a flux that produced a current of $\sim 0.8-3 \mathrm{nA}$, as monitored with a Faraday cup. Here $\mathrm{pBQ}$ vapour that had sublimed from a crystalline pBQ sample (Sigma-Aldrich, $>98 \%$ assay), which was heated to $\sim 55^{\circ} \mathrm{C}$, flowed through a $0.7 \mathrm{~mm}$ internal diameter needle to form the molecular beam. In this study, the gas lines and leak valve transporting the $\mathrm{pBQ}$ vapour, and also the apparatus vacuum chamber, were all heated to $70{ }^{\circ} \mathrm{C}$ to minimize recrystallization of $\mathrm{pBQ}$. Electrons interacting with $\mathrm{pBQ}$ and scattering into a rotatable analyser (located at an angle, $\theta$, with respect to the incident beam direction) are transported with electrostatic lenses to a hemispherical energy analyser. Those electrons with the correct scattered electron energy $\left(E_{\mathrm{s}}\right)$ pass through the analyser and are finally detected using a channel electron multiplier. Here the EELS were obtained by using a multichannel scaler to record the number of electrons detected while repeatedly ramping over a range of energy loss values $\left(E_{\mathrm{L}}=E_{0}-E_{\mathrm{s}}\right)$. In the present work, electron energy loss spectra (EELS) are recorded for the fixed incident electron energies $\left(E_{0}\right)$ of 20,30 , and $40 \mathrm{eV}$ at discrete scattered electron angles in the range $\theta=10^{\circ}-90^{\circ}$. These EELS were measured with a chamber pressure typically of the order of $\sim 2-3 \times 10^{-6}$ Torr, but always below $5 \times 10^{-6}$ Torr, which makes multiple scattering events unlikely. The present instrumental energy resolution was typically $\sim 80 \mathrm{meV}$ (full width at half maximum, FWHM).

The measured EELS are composed of intensity contributions for distinct scattering processes, such as elastic, vibrational, and electronic-state excitations. To interpret the EELS, each spectrum is deconvoluted into components that arise from particular scattering events or a combination of energetically unresolved scattering events using a least squares fitting procedure. Here our spectrum is deconvoluted using a single Gaussian function, or a combination of Gaussian functions, to represent the energy-loss features. Typical results for the fitting process are given in Fig. 1 for two different kinematical conditions. The peak positions and widths of these Gaussian functions are contained in Table I. Here the intensity ratio of the inelastic to elastic scattering features $\left(I_{i} / I_{0}\right)$ is equal to the ratio of the differential cross sections for the inelastic and elastic cross sections, $\sigma_{i}\left(E_{0}, \theta\right)$ and $\sigma_{0}\left(E_{0}, \theta\right)$, respectively, after correcting for any variation in the analyser transmission

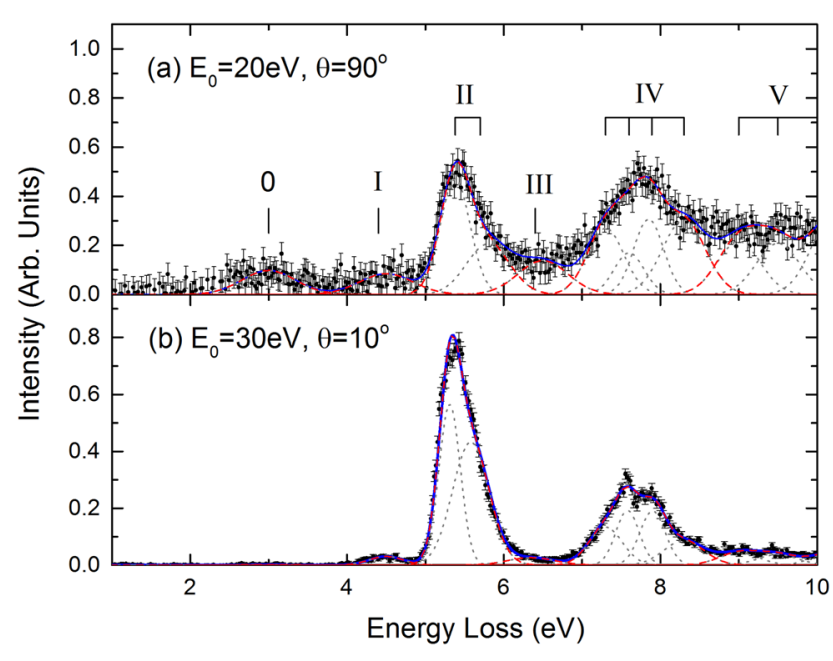

FIG. 1. Electron energy loss spectra obtained at (a) $E_{0}=20 \mathrm{eV}, \theta=90^{\circ}$ and (b) $E_{0}=30 \mathrm{eV}, \theta=10^{\circ}$. Here the solid blue curve represents the overall fit to the energy loss spectra obtained through the least squares fitting. Here the dashed red curves show the fitting components for the composite electronic state bands $0-\mathrm{V}$, while the gray short-dashed curves show the individual Gaussian functions that contribute to the composite electronic state bands. Refer to the text and Table I for further details on the fitting procedure and fitting parameters.

efficiency $(\eta)$ for electrons scattering with elastic or inelastic energies,

$$
\sigma_{i}\left(E_{0}, \theta\right)=\eta \frac{I_{i}}{I_{0}} \sigma_{0}\left(E_{0}, \theta\right) .
$$

Following Allan, ${ }^{55}$ we employ a negative voltage ramp to maintain the transmission properties of the analyser for electrons with varying scattered electron energies. With this procedure, for the incident electron energies in the $20-40 \mathrm{eV}$ range and energy loss values up to $\sim 10.5 \mathrm{eV}$ of the present investigation, the analyser transmission function is essentially unity to within an uncertainty of $20 \%$. Under these circumstances, it follows from Eq. (1) that the measured inelastic to elastic intensity ratio can be converted to an inelastic DCS for electron impact excitation provided that the absolute elastic DCS for electron impact, at the same $E_{0}$ and $\theta$, is known. As there are currently no experimental data for elastic scattering from $\mathrm{pBQ}$ that we can use for the normalization, we have normalized our inelastic DCS data to our earlier theoretical elastic Schwinger multichannel method with pseudopotential (SMCPP) calculation results. ${ }^{56}$ The rationale for using the theoretical elastic SMCPP calculation results to describe the electron-impact elastic scattering DCS behaviour for $\mathrm{pBQ}$ is discussed in detail in the work of Jones et al. ${ }^{56}$ to whom the reader is referred. As the SMCPP typically reproduces the electron-impact elastic scattering DCS behaviour to better than $10 \%$, we employ this value as a conservative uncertainty estimate for the elastic scattering DCS. This uncertainty on the theoretical elastic DCS data is combined in quadrature with the uncertainties on the inelastic to elastic scattering intensity ratio (which includes statistical uncertainties on the experimental data and the uncertainty arising from the least-squares deconvolution) and the transmission efficiency to obtain the quoted uncertainties on the experimental DCS for electronimpact excitation of the composite electronic-state bands. Here the overall experimental uncertainties typically range between 
TABLE I. The pBQ composite electronic-state feature peak positions, widths (FWHM), and the MOB-SCI state assignments.

\begin{tabular}{|c|c|c|c|c|c|c|}
\hline \multirow[b]{2}{*}{ Band } & \multicolumn{2}{|c|}{ Experiment } & \multicolumn{4}{|c|}{ MOB-SCI/5s5p2d } \\
\hline & $\begin{array}{c}\text { Position } \\
(\mathrm{eV})\end{array}$ & $\begin{array}{l}\text { Width } \\
(\mathrm{eV})\end{array}$ & $\begin{array}{c}\text { Singlet } \\
\text { assignments }\end{array}$ & $\begin{array}{l}\text { Excitation } \\
\text { energy }(e V)\end{array}$ & $\begin{array}{c}\text { Triplet } \\
\text { assignments }\end{array}$ & $\begin{array}{l}\text { Excitation } \\
\text { energy }(e V)\end{array}$ \\
\hline Elastic & 0.00 & 0.08 & & & & \\
\hline Band 0 & 3.0 & 0.78 & $\begin{array}{l}{ }^{1} \mathrm{~B}_{1 \mathrm{~g}} \\
{ }^{1} \mathrm{~A}_{\mathrm{u}}\end{array}$ & $\begin{array}{l}5.26 \\
5.58\end{array}$ & $\begin{array}{c}{ }^{3} B_{1 g} \\
{ }^{3} \mathrm{~A}_{\mathrm{u}} \\
{ }^{3} \mathrm{~B}_{1 \mathrm{u}} \\
{ }^{3} \mathrm{~B}_{3 \mathrm{~g}}\end{array}$ & $\begin{array}{l}4.81 \\
5.11 \\
2.96 \\
3.29\end{array}$ \\
\hline Band I & 4.38 & 0.66 & ${ }^{1} \mathrm{~B}_{3 \mathrm{~g}}$ & 5.85 & $\begin{array}{l}{ }^{3} \mathrm{~B}_{1 \mathrm{u}} \\
{ }^{3} \mathrm{~A}_{\mathrm{g}}\end{array}$ & $\begin{array}{l}6.49 \\
6.74\end{array}$ \\
\hline Band II & $\begin{array}{l}5.37 \\
5.73\end{array}$ & $\begin{array}{l}0.41 \\
0.61\end{array}$ & ${ }^{1} \mathrm{~B}_{1 \mathrm{u}}$ & 7.41 & $\begin{array}{l}{ }^{3} B_{3 u} \\
{ }^{3} B_{2 g} \\
{ }^{3} B_{1 g} \\
{ }^{3} B_{3 g} \\
{ }^{3} A_{u}\end{array}$ & $\begin{array}{c}8.61 \\
9.13 \\
9.00 \\
8.46 \\
10.1\end{array}$ \\
\hline Band III & 6.43 & 0.72 & $\begin{array}{l}{ }^{1} B_{3 u} \\
{ }^{1} B_{2 u}\end{array}$ & $\begin{array}{c}9.03 \\
10.1\end{array}$ & $\begin{array}{l}{ }^{3} B_{2 g} \\
{ }^{3} B_{1 g} \\
{ }^{3} B_{1 u} \\
{ }^{3} B_{3 u} \\
{ }^{3} B_{3 g} \\
{ }^{3} B_{2 u}\end{array}$ & $\begin{array}{c}10.6 \\
8.09 \\
9.02 \\
10.4 \\
9.68 \\
8.78\end{array}$ \\
\hline Band IV & $\begin{array}{l}7.29 \\
7.60 \\
7.85 \\
8.30\end{array}$ & $\begin{array}{l}0.52 \\
0.41 \\
0.41 \\
0.62\end{array}$ & & & & \\
\hline Band V & $\begin{array}{r}9.00 \\
9.50 \\
10.20\end{array}$ & $\begin{array}{l}0.62 \\
0.62 \\
0.62\end{array}$ & & & & \\
\hline
\end{tabular}

$22 \%$ and $30 \%$ for the electronic-state excitations that had reasonably high-intensity in the EELS. For electronic band features that presented with very weak intensity in the EELS, that were difficult to observe for this challenging target, the uncertainties ranged from $23 \%$ to $95 \%$, with those uncertainties being very sensitive to our ability to observe the weak features under the different experimental kinematics investigated in this study.

Inelastic differential scattering cross sections for electron impact excitation of $\mathrm{pBQ}$ electronic bands have also been determined using the Schwinger multichannel method with pseudo-potentials (SMCPPs). As this method has recently been reviewed in detail by da Costa et al.,${ }^{57}$ we will provide only a brief description here. In the SMCPP, the scattering amplitude is given by the following expression:

$$
f\left(\boldsymbol{k}_{f}, \boldsymbol{k}_{i}\right)=-\frac{1}{2 \pi} \sum_{m, n}\left\langle S_{\boldsymbol{k}_{f}}|V| \chi_{m}\right\rangle\left(d^{-1}\right)_{m n}\left\langle\chi_{n}|V| S_{\boldsymbol{k}_{i}}\right\rangle,
$$

where

$d_{m n}=\left\langle\chi_{m}\left|\left[\frac{\hat{H}}{N+1}-\frac{\hat{H} P+P \hat{H}}{2}+\frac{P V+V P}{2}-V G_{P}^{(+)} V\right]\right| \chi_{n}\right\rangle$.
In Eqs. (2) and (3), $P$ is an operator projecting onto the energetically open channels $\left(N_{\text {open }}\right)$,

$$
P=\sum_{l=1}^{N_{\text {open }}}\left|\Phi_{l}\right\rangle\left\langle\Phi_{l}\right|
$$

$G_{P}^{(+)}$is the free particle Green's function projected onto P-space, $\hat{H}=E-H$ is the total electron energy (ground state plus kinetic energy of projectile) minus the Hamiltonian for the $(N+1)$-electron system within the fixed nuclei approximation, and $\boldsymbol{k}_{i}\left(\boldsymbol{k}_{f}\right)$ is the incoming (outgoing) projectile wave vector. Here $H=H_{0}+V$ is the sum of the Hamiltonian describing the non-interacting $N$-electron system $\left(H_{0}\right)$ and the electron-target interaction potential $(V) . S_{k}$ is the solution of $H_{0}$, namely, the product of a plane wave describing the incident projectile and a target state, $\left|\Phi_{l}\right\rangle$. For the expansion of the variational scattering wave function, the method makes use of a trial basis sets composed of $(N+1)$-particle configuration state functions (CSFs). These CSFs, denoted by $\left|\chi_{m}\right\rangle$ and built from spin-adapted, anti-symmetrized products of target electronic states and projectile scattering orbitals, are given by 


$$
\left|\chi_{m}\right\rangle=\mathcal{A}_{N+1}\left|\Phi_{i}(1, \ldots, N)\right\rangle \otimes\left|\varphi_{j}(N+1)\right\rangle,
$$

where for $\mathrm{i}>0,\left|\Phi_{i}\right\rangle \equiv{ }^{(2 \mathrm{~S}+1)}\left(\mathrm{h}_{\mathrm{i}} \rightarrow \mathrm{p}_{\mathrm{i}}\right)$ is a singly excited state obtained by promoting one electron from the ground state (giving rise to a hole orbital $h_{\mathrm{i}}$ ) to a particle orbital $\mathrm{p}_{\mathrm{i}}$, with either singlet $(S=0)$ or triplet $(S=1)$ spin coupling. In practical applications considered so far, only $(N+1)$-electron configurations with total spin $\mathrm{S}=1 / 2$ (doublets) are actually taken into account. The present implementation of the SMCPP takes advantage of parallel computing and makes use of the minimal orbital basis for single configuration interaction (MOB-SCI) strategy, so as to provide a good balance of all aspects that are relevant for the description of electron scattering from complex targets like $\mathrm{pBQ}$. The computations presented in this paper were all performed using a channel coupling scheme where up to 89-channels are open. As discussed in our previous work, ${ }^{16}$ the hole-particle pairs used in the present MOB-SCI calculation were selected in order to replicate the spectrum obtained according to the full single configuration interaction (SCI) approximation. Calculations are performed in the body-fixed frame but can be converted into the laboratory frame through a partial wave expansion, $|l m\rangle$, of the plane waves in terms of spherical harmonics. In our calculations, the partial waves included in the expansion, $l$, are truncated and include partial waves up to a maximum value $L_{\max }$. In the present work, we investigate the convergence of the DCSs by considering $L_{\max }=7$, 10 , and 13 , with $L_{\max }=13$ achieving convergence for the SMCPP scattering amplitude [Eq. (2)] describing the excitation processes. In this work, we also implement a Bornclosure scheme where the scattering amplitude is expressed through

$$
\begin{aligned}
f_{L A B}^{\text {closure }}\left(\boldsymbol{k}_{f}, \boldsymbol{k}_{i}\right)= & f_{L A B}^{F B A}\left(\boldsymbol{k}_{f}, \boldsymbol{k}_{i}\right)+\sum_{l=0}^{L_{\max }} \sum_{m=-l}^{l}\left(f_{L A B}\left(\operatorname{lm}, k_{f}, \boldsymbol{k}_{i}\right)\right. \\
& \left.-f_{L A B}^{F B A}\left(\operatorname{lm}, k_{f}, \boldsymbol{k}_{i}\right)\right) Y_{l m}^{*}\left(\hat{\boldsymbol{k}}_{f}\right) .
\end{aligned}
$$

Here $f_{L A B}^{F B A}$ is the plane wave amplitude for the transition dipole moment obtained within the first Born approximation in the lab-frame, while $\hat{\boldsymbol{k}}_{f}$ denotes the outgoing direction in the molecule-fixed frame. In the discussion that follows, we highlight the distinction between our SMCPP results with closure, i.e., those that are obtained using Eq. (6) and those from our SMCPP results (without closure) that are obtained with Eq. (2). Further details of the SMCPP implementation for the quinone target will be given elsewhere. ${ }^{58}$

\section{RESULTS AND DISCUSSION}

In Fig. 1, we show typical electron energy loss spectra obtained for $\mathrm{pBQ}$ under two different experimental conditions. In spectrum (a), measured at a relatively low incident electron energy of $E_{0}=20 \mathrm{eV}$ and a large scattering angle of $\theta=90^{\circ}$, we can expect that both direct (dipole allowed) and exchange-type (optically forbidden) excitation processes can occur. In spectrum (b), obtained at a somewhat larger incident electron energy $E_{0}=30 \mathrm{eV}$ and smaller scattered electron angle, $\theta=10^{\circ}$, the dipole and spin allowed transitions are favoured, and the energy loss spectrum is similar to the photo-absorption spectrum we previously reported. ${ }^{16}$ What is particularly apparent when comparing these two spectra is the appearance of a feature, band 0 , at $E_{\mathrm{L}} \sim 3.0 \mathrm{eV}$ in the spectrum (a) where singlet-triplet and symmetry forbidden excitation processes can occur. Our previous timedependent density functional theory (TD-DFT) calculations ${ }^{16}$ indicated that four-triplet states and two-symmetry forbidden transitions may be found in this energy loss region. This feature has also previously been observed by Allan ${ }^{59}$ in fixed angle energy loss spectra obtained at constant residual electron energy. Also shown in this figure are the five electron energy loss features which are present when the electron energy loss spectrum is obtained under kinematic conditions which favour dipole-allowed excitation processes. The spectral positions of the composite electronic features (bands) are summarised in Table I. In this table, we also report our present assignments for the corresponding theoretical electronic-state excitation processes, obtained according to the MOB-SCI strategy, of the composite experimental bands.

DCSs for the composite electronic-state bands 0-V have been obtained in this work, in the manner discussed in Sec. II, and are shown in Figs. 2-6. Our experimental DCSs are also tabulated in Tables II-VII. In these tables, we additionally include our measured inelastic to elastic scattering DCS ratios

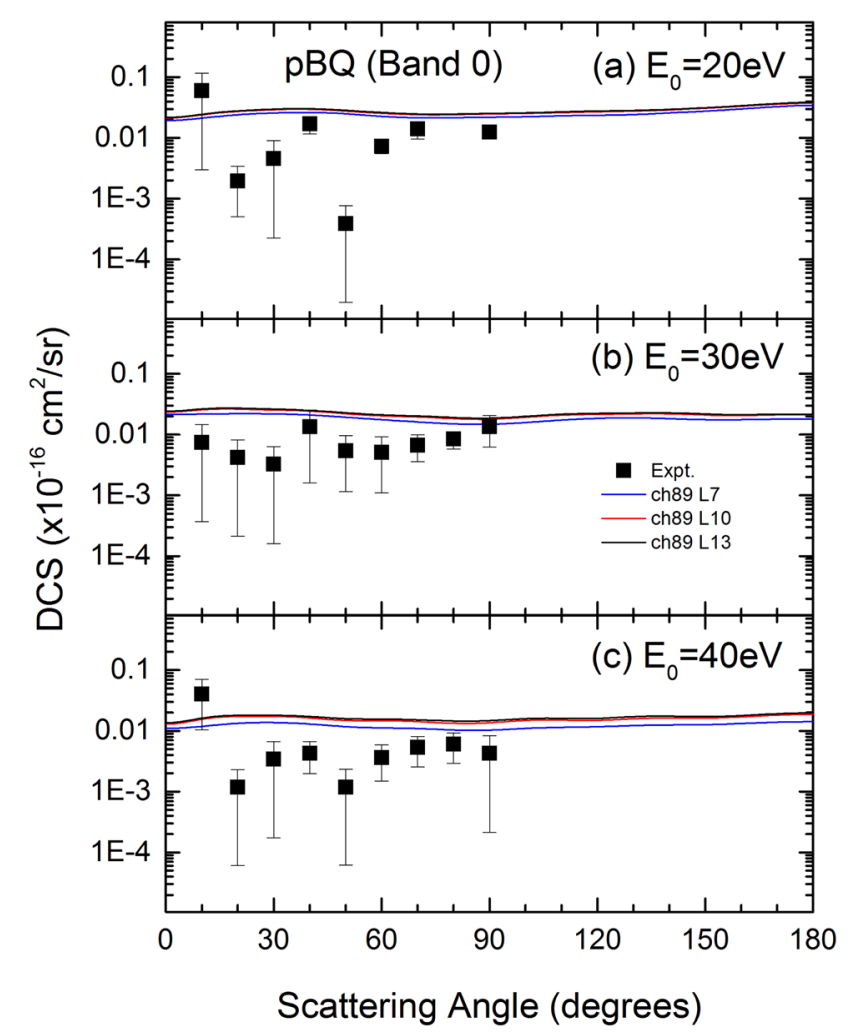

FIG. 2. Experimental and theoretical differential cross sections for electron impact excitation of composite electronic band 0 of pBQ $\left(E_{\mathrm{L}}=3.0 \mathrm{eV}\right)$ at impact energies of (a) $E_{0}=20 \mathrm{eV}$, (b) $E_{0}=30 \mathrm{eV}$, and (c) $E_{0}=40 \mathrm{eV}$. See the legend in the figure and text for further details. 


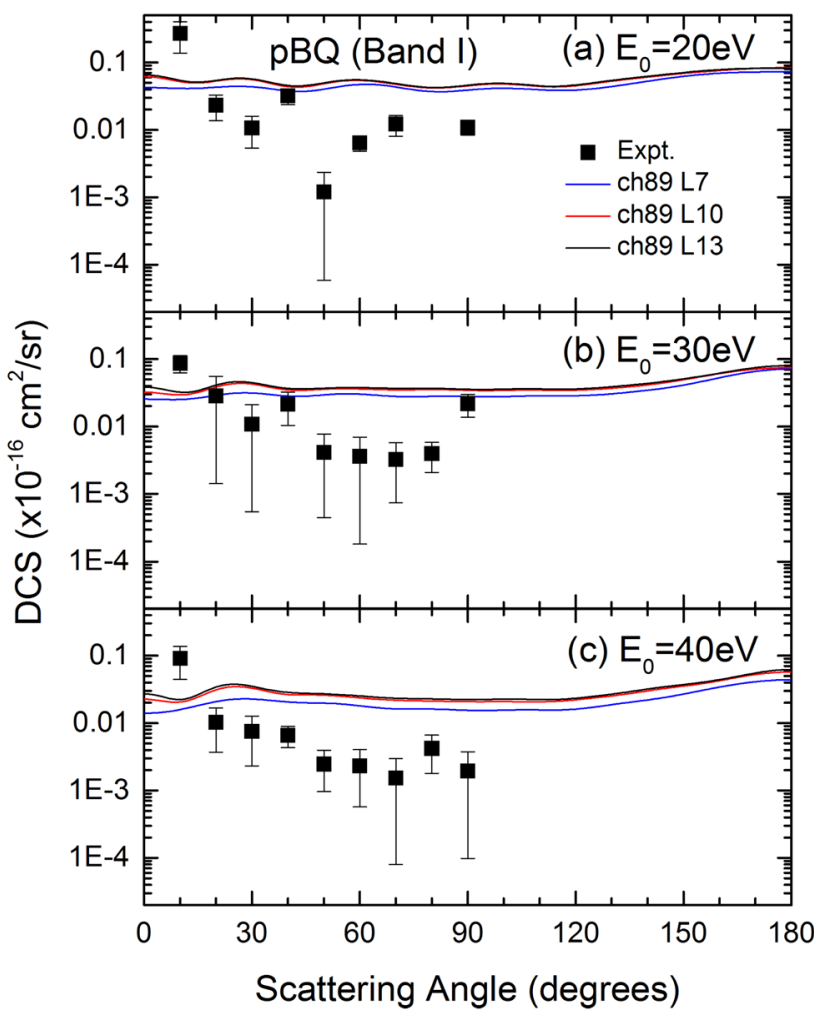

FIG. 3. Experimental and theoretical differential cross sections for electron impact excitation of composite electronic band $\mathrm{I}\left(\mathrm{E}_{\mathrm{L}} \sim 4.38 \mathrm{eV}\right)$ of $\mathrm{pBQ}$ at impact energies of (a) $E_{0}=20 \mathrm{eV}$, (b) $E_{0}=30 \mathrm{eV}$, and (c) $E_{0}=40 \mathrm{eV}$. See the legend in the figure and text for further details.

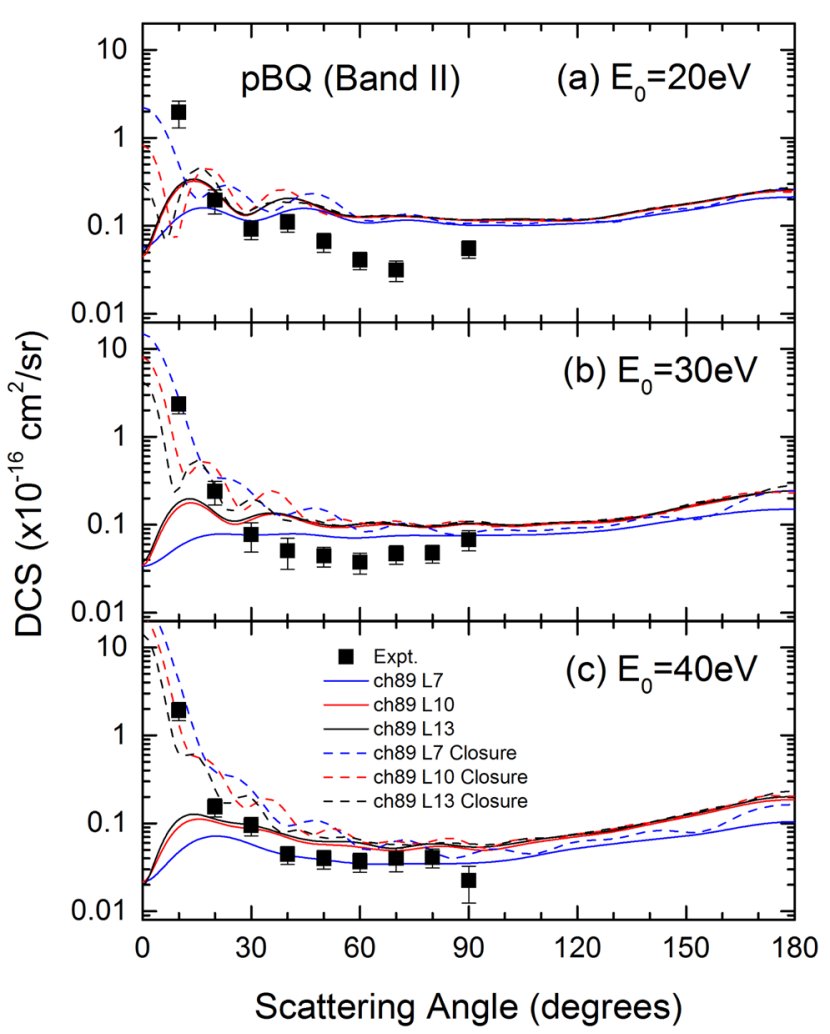

FIG. 4. Experimental and theoretical differential cross sections for electron impact excitation of composite electronic band II $\left(\mathrm{E}_{\mathrm{L}} \sim 5.37-5.73 \mathrm{eV}\right)$ of $\mathrm{pBQ}$ at impact energies of (a) $E_{0}=20 \mathrm{eV}$, (b) $E_{0}=30 \mathrm{eV}$, and (c) $E_{0}=40 \mathrm{eV}$. See the legend in the figure and text for further details.

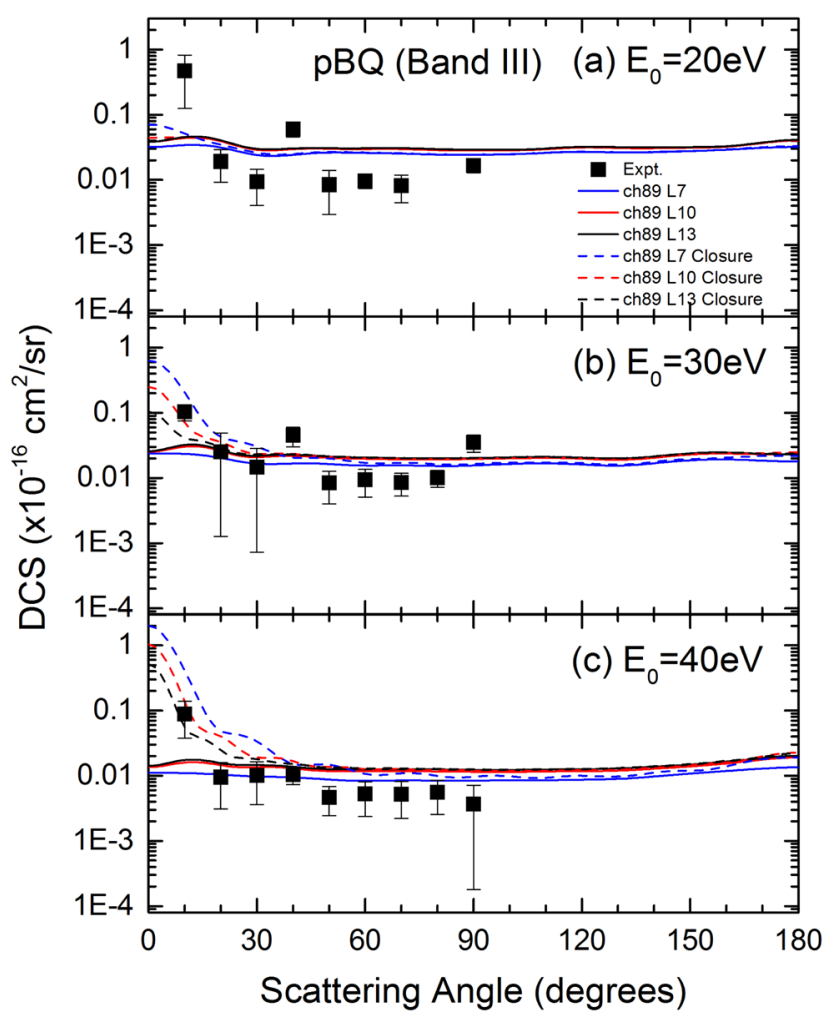

FIG. 5. Experimental and theoretical differential cross sections for electron impact excitation of composite electronic band III $\left(\mathrm{E}_{\mathrm{L}} \sim 6.4 \mathrm{eV}\right)$ of $\mathrm{pBQ}$ at impact energies of (a) $E_{0}=20 \mathrm{eV}$, (b) $E_{0}=30 \mathrm{eV}$, and (c) $E_{0}=40 \mathrm{eV}$. See the legend in the figure and text for further details.

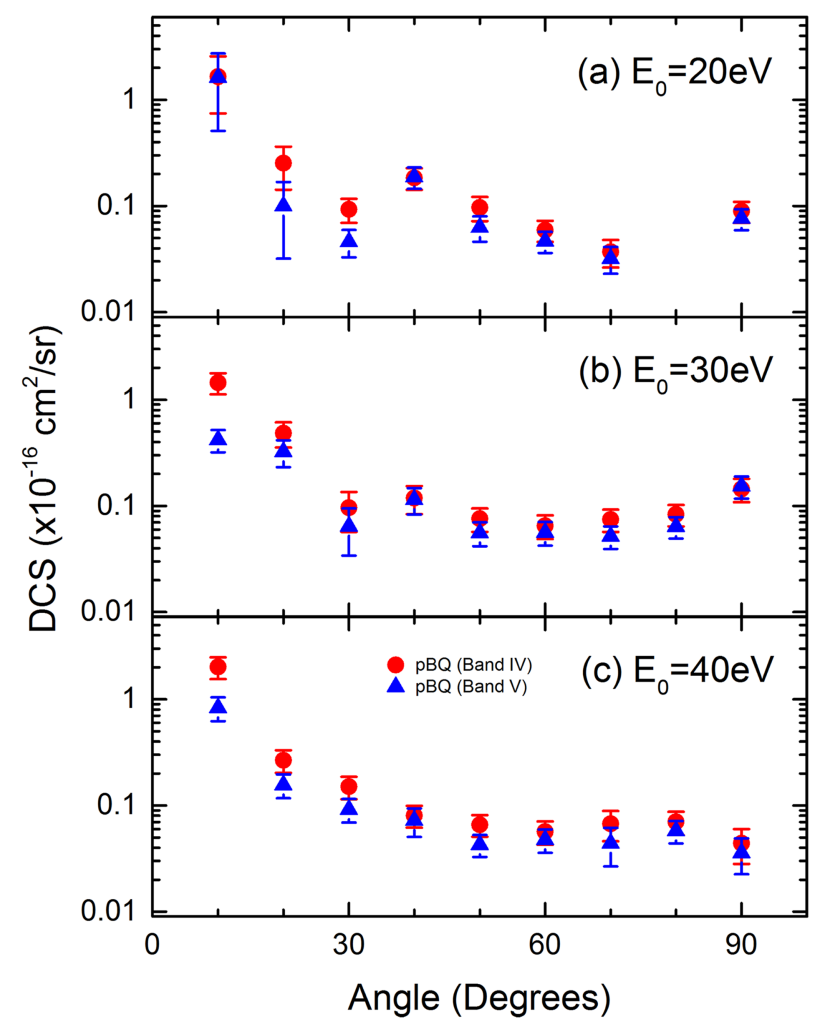

FIG. 6. Experimental differential cross sections for electron impact excitation of composite electronic band IV $\left(\mathrm{E}_{\mathrm{L}} \sim 7.29-8.30 \mathrm{eV}\right)$ and band $\mathrm{V}\left(\mathrm{E}_{\mathrm{L}} \sim 9.0\right.$ $10.2 \mathrm{eV}$ ) of pBQ at impact energies of (a) $E_{0}=20 \mathrm{eV}$, (b) $E_{0}=30 \mathrm{eV}$, and (c) $E_{0}=40 \mathrm{eV}$. See the legend in the figure and text for further details. 
TABLE II. Differential cross sections $\left(\times 10^{-16} \mathrm{~cm}^{2} / \mathrm{sr}\right)$ for excitation of the electronic band $0\left(E_{\mathrm{L}} \sim 3.0 \mathrm{eV}\right)$ of $\mathrm{pBQ}$.

\begin{tabular}{|c|c|c|c|c|c|c|c|c|c|}
\hline \multirow{2}{*}{$\begin{array}{l}\text { Angle } \\
\text { (deg) }\end{array}$} & \multicolumn{3}{|c|}{$E_{0}=20 \mathrm{eV}$} & \multicolumn{3}{|c|}{$E_{0}=30 \mathrm{eV}$} & \multicolumn{3}{|c|}{$E_{0}=40 \mathrm{eV}$} \\
\hline & Ratio & DCS & Uncert. (\%) & Ratio & DCS & Uncert. (\%) & Ratio & DCS & Uncert. $(\%)$ \\
\hline 10 & $1.01 \times 10^{-3}$ & $5.98 \times 10^{-2}$ & 95 & $1.33 \times 10^{-4}$ & $7.47 \times 10^{-3}$ & 95 & $7.87 \times 10^{-4}$ & $4.04 \times 10^{-2}$ & 74 \\
\hline 20 & $1.07 \times 10^{-4}$ & $1.95 \times 10^{-3}$ & 74 & $3.27 \times 10^{-4}$ & $4.19 \times 10^{-3}$ & 95 & $1.26 \times 10^{-4}$ & $1.18 \times 10^{-3}$ & 95 \\
\hline 30 & $1.56 \times 10^{-3}$ & $4.61 \times 10^{-3}$ & 95 & $1.81 \times 10^{-3}$ & $3.26 \times 10^{-3}$ & 95 & $2.10 \times 10^{-3}$ & $3.40 \times 10^{-3}$ & 95 \\
\hline 40 & $1.70 \times 10^{-2}$ & $1.70 \times 10^{-2}$ & 32 & $1.37 \times 10^{-2}$ & $1.36 \times 10^{-2}$ & 88 & $3.89 \times 10^{-3}$ & $4.32 \times 10^{-3}$ & 54 \\
\hline 50 & $4.82 \times 10^{-4}$ & $3.92 \times 10^{-4}$ & 95 & $6.05 \times 10^{-3}$ & $5.41 \times 10^{-3}$ & 79 & $1.28 \times 10^{-3}$ & $1.19 \times 10^{-3}$ & 95 \\
\hline 60 & $9.80 \times 10^{-3}$ & $7.31 \times 10^{-3}$ & 24 & $6.09 \times 10^{-3}$ & $5.13 \times 10^{-3}$ & 79 & $4.53 \times 10^{-3}$ & $3.68 \times 10^{-3}$ & 59 \\
\hline 70 & $2.00 \times 10^{-2}$ & $1.40 \times 10^{-2}$ & 32 & $9.26 \times 10^{-3}$ & $6.73 \times 10^{-3}$ & 47 & $7.61 \times 10^{-3}$ & $5.35 \times 10^{-3}$ & 52 \\
\hline 80 & $\ldots$ & $\ldots$ & & $1.28 \times 10^{-2}$ & $8.48 \times 10^{-3}$ & 32 & $1.02 \times 10^{-2}$ & $6.11 \times 10^{-3}$ & 52 \\
\hline 90 & $1.92 \times 10^{-2}$ & $1.25 \times 10^{-2}$ & 23 & $1.97 \times 10^{-2}$ & $1.34 \times 10^{-2}$ & 54 & $7.00 \times 10^{-3}$ & $4.27 \times 10^{-3}$ & 95 \\
\hline
\end{tabular}

to facilitate, if needed, a renormalisation of our inelastic DCSs in the event that accurate and reliable experimental elastic DCSs for $\mathrm{pBQ}$ become available.

In Fig. 2, the experimental DCSs for band 0 are compared against the results from our theoretical calculations for this composite electronic feature. Our measured cross sections for band 0 are listed in Table II. The experimental DCSs are quasi-isotropic, showing minimal variation in magnitude over the angular range measured. This feature has a weak intensity and was difficult to observe experimentally, even at the lower incident electron energy of $20 \mathrm{eV}$. As a consequence, there are significant uncertainties associated with the measured cross sections that we report. In this case, we observe that the theoretical calculations overestimate the experimental data at all incident electron energies. From the theoretical perspective, the calculation appears to have converged at $L_{\max }=13$. Here the Born-dipole closure does not change the cross section as the transitions are not dipoleallowed.

The experimental and theoretical DCSs for electron impact excitation of the unresolved electronic states within band I are shown in Fig. 3 and listed in Table III. The experimental data display a forward peaked behaviour, having the highest cross-sectional intensity at the more forward scattering angles and decreasing in intensity as the scattered electron angle increases. This behaviour is characteristic of dipole-allowed excitations. Note that this feature is dominated by a forbidden $\pi \pi^{*}$ excitation to a ${ }^{1} B_{3 g}$ state that becomes

TABLE III. Differential cross sections $\left(\times 10^{-16} \mathrm{~cm}^{2} / \mathrm{sr}\right)$ for excitation of the electronic band $\mathrm{I}\left(\mathrm{E}_{\mathrm{L}} \sim 4.38 \mathrm{eV}\right)$ of $\mathrm{pBQ}$.

\begin{tabular}{|c|c|c|c|c|c|c|c|c|c|}
\hline \multirow{2}{*}{$\begin{array}{l}\text { Angle } \\
\text { (deg) }\end{array}$} & \multicolumn{3}{|c|}{$E_{0}=20 \mathrm{eV}$} & \multicolumn{3}{|c|}{$E_{0}=30 \mathrm{eV}$} & \multicolumn{3}{|c|}{$E_{0}=40 \mathrm{eV}$} \\
\hline & Ratio & DCS & Uncert. (\%) & Ratio & DCS & Uncert. (\%) & Ratio & DCS & Uncert. (\%) \\
\hline 10 & $4.53 \times 10^{-3}$ & $2.68 \times 10^{-1}$ & 49 & $1.55 \times 10^{-3}$ & $8.68 \times 10^{-2}$ & 28 & $1.77 \times 10^{-3}$ & $9.08 \times 10^{-2}$ & 51 \\
\hline 20 & $1.27 \times 10^{-3}$ & $2.32 \times 10^{-2}$ & 41 & $2.21 \times 10^{-3}$ & $2.84 \times 10^{-2}$ & 95 & $1.09 \times 10^{-3}$ & $1.02 \times 10^{-2}$ & 64 \\
\hline 30 & $3.62 \times 10^{-3}$ & $1.07 \times 10^{-2}$ & 50 & $5.99 \times 10^{-3}$ & $1.08 \times 10^{-2}$ & 95 & $4.64 \times 10^{-3}$ & $7.51 \times 10^{-3}$ & 69 \\
\hline 40 & $3.17 \times 10^{-2}$ & $3.18 \times 10^{-2}$ & 25 & $2.16 \times 10^{-2}$ & $2.15 \times 10^{-2}$ & 52 & $5.96 \times 10^{-3}$ & $6.63 \times 10^{-3}$ & 35 \\
\hline 50 & $1.47 \times 10^{-3}$ & $1.20 \times 10^{-3}$ & 95 & $4.58 \times 10^{-3}$ & $4.10 \times 10^{-3}$ & 89 & $2.64 \times 10^{-3}$ & $2.46 \times 10^{-3}$ & 61 \\
\hline 60 & $8.56 \times 10^{-3}$ & $6.38 \times 10^{-3}$ & 25 & $4.26 \times 10^{-3}$ & $3.58 \times 10^{-3}$ & 95 & $2.85 \times 10^{-3}$ & $2.31 \times 10^{-3}$ & 75 \\
\hline 70 & $1.74 \times 10^{-2}$ & $1.22 \times 10^{-2}$ & 34 & $4.45 \times 10^{-3}$ & $3.23 \times 10^{-3}$ & 77 & $2.17 \times 10^{-3}$ & $1.52 \times 10^{-3}$ & 95 \\
\hline 80 & $\ldots$ & $\ldots$ & & $5.94 \times 10^{-3}$ & $3.95 \times 10^{-3}$ & 47 & $7.00 \times 10^{-3}$ & $4.20 \times 10^{-3}$ & 57 \\
\hline 90 & $1.67 \times 10^{-2}$ & $1.08 \times 10^{-2}$ & 23 & $3.20 \times 10^{-2}$ & $2.18 \times 10^{-2}$ & 38 & $3.17 \times 10^{-3}$ & $1.93 \times 10^{-3}$ & 95 \\
\hline
\end{tabular}

TABLE IV. Differential cross sections $\left(\times 10^{-16} \mathrm{~cm}^{2} / \mathrm{sr}\right)$ for excitation of the electronic band II $\left(\mathrm{E}_{\mathrm{L}} \sim 5.37-5.73 \mathrm{eV}\right)$ of $\mathrm{pBQ}$.

\begin{tabular}{|c|c|c|c|c|c|c|c|c|c|}
\hline \multirow{2}{*}{$\begin{array}{l}\text { Angle } \\
\text { (deg) }\end{array}$} & \multicolumn{3}{|c|}{$E_{0}=20 \mathrm{eV}$} & \multicolumn{3}{|c|}{$E_{0}=30 \mathrm{eV}$} & \multicolumn{3}{|c|}{$E_{0}=40 \mathrm{eV}$} \\
\hline & Ratio & DCS & Uncert. (\%) & Ratio & DCS & Uncert. (\%) & Ratio & DCS & Uncert. $(\%)$ \\
\hline 10 & $3.32 \times 10^{-2}$ & 1.96 & 34 & $4.19 \times 10^{-2}$ & 2.35 & 22 & $3.74 \times 10^{-2}$ & 1.92 & 23 \\
\hline 20 & $1.08 \times 10^{-2}$ & $1.96 \times 10^{-1}$ & 30 & $1.88 \times 10^{-2}$ & $2.41 \times 10^{-1}$ & 30 & $1.65 \times 10^{-2}$ & $1.55 \times 10^{-1}$ & 24 \\
\hline 30 & $3.10 \times 10^{-2}$ & $9.14 \times 10^{-2}$ & 23 & $4.30 \times 10^{-2}$ & $7.75 \times 10^{-2}$ & 37 & $5.85 \times 10^{-2}$ & $9.48 \times 10^{-2}$ & 24 \\
\hline 40 & $1.10 \times 10^{-1}$ & $1.10 \times 10^{-1}$ & 23 & $5.11 \times 10^{-2}$ & $5.07 \times 10^{-2}$ & 38 & $4.00 \times 10^{-2}$ & $4.45 \times 10^{-2}$ & 23 \\
\hline 50 & $8.14 \times 10^{-2}$ & $6.61 \times 10^{-2}$ & 25 & $4.98 \times 10^{-2}$ & $4.45 \times 10^{-2}$ & 26 & $4.27 \times 10^{-2}$ & $3.99 \times 10^{-2}$ & 24 \\
\hline 60 & $5.49 \times 10^{-2}$ & $4.09 \times 10^{-2}$ & 22 & $4.48 \times 10^{-2}$ & $3.77 \times 10^{-2}$ & 26 & $4.52 \times 10^{-2}$ & $3.67 \times 10^{-2}$ & 24 \\
\hline 70 & $4.51 \times 10^{-2}$ & $3.16 \times 10^{-2}$ & 26 & $6.47 \times 10^{-2}$ & $4.70 \times 10^{-2}$ & 24 & $5.72 \times 10^{-2}$ & $4.02 \times 10^{-2}$ & 30 \\
\hline 80 & $\ldots$ & $\ldots$ & & $7.16 \times 10^{-2}$ & $4.76 \times 10^{-2}$ & 23 & $6.84 \times 10^{-2}$ & $4.11 \times 10^{-2}$ & 24 \\
\hline 90 & $8.46 \times 10^{-2}$ & $5.50 \times 10^{-2}$ & 22 & $9.98 \times 10^{-2}$ & $6.79 \times 10^{-2}$ & 26 & $3.68 \times 10^{-2}$ & $2.25 \times 10^{-2}$ & 45 \\
\hline
\end{tabular}


TABLE V. Differential cross sections $\left(\times 10^{-16} \mathrm{~cm}^{2} / \mathrm{sr}\right)$ for excitation of the electronic band III $\left(E_{\mathrm{L}} \sim 6.43 \mathrm{eV}\right)$ of $\mathrm{pBQ}$.

\begin{tabular}{|c|c|c|c|c|c|c|c|c|c|}
\hline \multirow{2}{*}{$\begin{array}{l}\text { Angle } \\
\text { (deg) }\end{array}$} & \multicolumn{3}{|c|}{$E_{0}=20 \mathrm{eV}$} & \multicolumn{3}{|c|}{$E_{0}=30 \mathrm{eV}$} & \multicolumn{3}{|c|}{$E_{0}=40 \mathrm{eV}$} \\
\hline & Ratio & DCS & Uncert. (\%) & Ratio & DCS & Uncert. (\%) & Ratio & DCS & Uncert. (\%) \\
\hline 10 & $7.97 \times 10^{-3}$ & $4.71 \times 10^{-1}$ & 74 & $1.85 \times 10^{-3}$ & $1.04 \times 10^{-1}$ & 28 & $1.72 \times 10^{-3}$ & $8.81 \times 10^{-2}$ & 57 \\
\hline 20 & $1.05 \times 10^{-3}$ & $1.92 \times 10^{-2}$ & 52 & $1.96 \times 10^{-3}$ & $2.52 \times 10^{-2}$ & 95 & $1.01 \times 10^{-3}$ & $9.48 \times 10^{-3}$ & 68 \\
\hline 30 & $3.17 \times 10^{-3}$ & $9.33 \times 10^{-3}$ & 56 & $8.10 \times 10^{-3}$ & $1.46 \times 10^{-2}$ & 95 & $6.22 \times 10^{-3}$ & $1.01 \times 10^{-2}$ & 64 \\
\hline 40 & $5.97 \times 10^{-2}$ & $5.99 \times 10^{-2}$ & 23 & $4.55 \times 10^{-2}$ & $4.51 \times 10^{-2}$ & 33 & $9.42 \times 10^{-3}$ & $1.05 \times 10^{-2}$ & 30 \\
\hline 50 & $1.04 \times 10^{-2}$ & $8.44 \times 10^{-3}$ & 65 & $9.38 \times 10^{-3}$ & $8.39 \times 10^{-3}$ & 52 & $4.96 \times 10^{-3}$ & $4.63 \times 10^{-3}$ & 47 \\
\hline 60 & $1.29 \times 10^{-2}$ & $9.63 \times 10^{-3}$ & 23 & $1.11 \times 10^{-2}$ & $9.36 \times 10^{-3}$ & 46 & $6.45 \times 10^{-3}$ & $5.23 \times 10^{-3}$ & 55 \\
\hline 70 & $1.16 \times 10^{-2}$ & $8.15 \times 10^{-3}$ & 45 & $1.18 \times 10^{-2}$ & $8.54 \times 10^{-3}$ & 38 & $7.41 \times 10^{-3}$ & $5.21 \times 10^{-3}$ & 58 \\
\hline 80 & $\ldots$ & $\ldots$ & & $1.52 \times 10^{-2}$ & $1.01 \times 10^{-2}$ & 29 & $9.23 \times 10^{-3}$ & $5.54 \times 10^{-3}$ & 54 \\
\hline 90 & $2.55 \times 10^{-2}$ & $1.66 \times 10^{-2}$ & 23 & $5.17 \times 10^{-2}$ & $3.52 \times 10^{-2}$ & 29 & $5.99 \times 10^{-3}$ & $3.66 \times 10^{-3}$ & 95 \\
\hline
\end{tabular}

quasi-dipole-allowed through vibronic coupling. This is clearly evident from the intensity and structure of this band in the high-resolution photo-absorption data in Ref. 16. Here the theoretical calculations, employing the fixed nuclear approximation, do not reproduce the experimentally observed forward peaked behaviour and, again, overestimate the magnitude of the cross section for most of the scattered electron angles. We can see in Fig. 3 that the agreement between the SMCPP and experimental results appears to worsen as the incident electron energy increases from 20 to $40 \mathrm{eV}$.

The DCSs for band II are shown in Fig. 4, with our experimental data listed in Table IV. This band is prominent in the photo-absorption spectrum, ${ }^{16}$ being predominantly assigned to the excitation to a ${ }^{1} \mathrm{~B}_{1 \mathrm{u}}$ state that has a significant optical oscillator strength. The strongly forward peaked behaviour of the differential cross section is characteristic of a dipoleallowed electronic excitation. ${ }^{51}$ From the theoretical perspective, the DCSs display some oscillatory behaviour, particularly in the case where the higher partial waves were included through the Born-closure procedure. As the SMCPP is an $L^{2}$ based method, the higher partial waves may differ from those used with the Born-closure approximation and so induce oscillations, owing to the different long-range interactions and the absence of flux competition within the dipole model. Here the partial waves are different as the $L^{2}$-method has difficulties describing the long range potential. At the lowest incident electron energy of $20 \mathrm{eV}$, see Fig. 4(a), the theoretical DCS is larger in magnitude than the experimental data for most scattering angles considered. As the incident electron energy increases, the theoretical calculations yield somewhat better agreement, particularly at the middle scattered electron angles, with the experimental results. Here we would anticipate the theoretical methods to yield results in better agreement with experiments at smaller incident electron energies. The origin of this deviation, at the lower incident electron energy, may therefore reflect an overestimation of contributions from non-dipoleallowed excitations (spin- or symmetry-forbidden), which may contribute more at lower incident electron energies but then decay rapidly in magnitude as the incident electron energy increases.

In Fig. 5, we present our results for the experimental and theoretical differential cross sections for the electronic excitation of states within band III. The experimental cross sections are also listed in Table V. Once again, this band is clearly evident in the photo-absorption spectrum, ${ }^{16}$ although the absence of structure in that photo-absorption spectrum suggests that the excited state is dissociative or undergoes nuclear rearrangement. The experimental DCSs again show a forward-peaked character, which is also reproduced theoretically using the Born-dipole closure scheme. Here we see that the theory slightly overestimates the magnitude of the cross section. The theoretical SMCPP cross section is quasiisotropic, except where it is dominated by the dipole-closure effect at scattering angles $\theta<40^{\circ}$. While the experimental statistics exhibit some undesirable scatter here, owing to the difficulty in measuring relatively small cross sections with

TABLE VI. Differential cross sections $\left(\times 10^{-16} \mathrm{~cm}^{2} / \mathrm{sr}\right)$ for excitation of the electronic band IV $\left(E_{\mathrm{L}} \sim 7.29-8.30 \mathrm{eV}\right)$ of $\mathrm{pBQ}$.

\begin{tabular}{|c|c|c|c|c|c|c|c|c|c|}
\hline \multirow{2}{*}{$\begin{array}{l}\text { Angle } \\
\text { (deg) }\end{array}$} & \multicolumn{3}{|c|}{$E_{0}=20 \mathrm{eV}$} & \multicolumn{3}{|c|}{$E_{0}=30 \mathrm{eV}$} & \multicolumn{3}{|c|}{$E_{0}=40 \mathrm{eV}$} \\
\hline & Ratio & DCS & Uncert. (\%) & Ratio & DCS & Uncert. (\%) & Ratio & DCS & Uncert. (\%) \\
\hline 10 & $2.79 \times 10^{-2}$ & 1.65 & 55 & $2.58 \times 10^{-2}$ & 1.45 & 22 & $3.93 \times 10^{-2}$ & 2.01 & 23 \\
\hline 20 & $1.39 \times 10^{-2}$ & $2.53 \times 10^{-1}$ & 44 & $3.77 \times 10^{-2}$ & $4.83 \times 10^{-1}$ & 27 & $2.84 \times 10^{-2}$ & $2.67 \times 10^{-1}$ & 24 \\
\hline 30 & $3.15 \times 10^{-2}$ & $9.29 \times 10^{-2}$ & 25 & $5.32 \times 10^{-2}$ & $9.61 \times 10^{-2}$ & 41 & $9.29 \times 10^{-2}$ & $1.50 \times 10^{-1}$ & 24 \\
\hline 40 & $1.83 \times 10^{-1}$ & $1.84 \times 10^{-1}$ & 23 & $1.20 \times 10^{-1}$ & $1.19 \times 10^{-1}$ & 29 & $7.23 \times 10^{-2}$ & $8.04 \times 10^{-2}$ & 23 \\
\hline 50 & $1.19 \times 10^{-1}$ & $9.67 \times 10^{-2}$ & 26 & $8.46 \times 10^{-2}$ & $7.57 \times 10^{-2}$ & 25 & $7.06 \times 10^{-2}$ & $6.59 \times 10^{-2}$ & 23 \\
\hline 60 & $7.95 \times 10^{-2}$ & $5.92 \times 10^{-2}$ & 23 & $7.74 \times 10^{-2}$ & $6.51 \times 10^{-2}$ & 25 & $6.99 \times 10^{-2}$ & $5.67 \times 10^{-2}$ & 25 \\
\hline 70 & $5.29 \times 10^{-2}$ & $3.71 \times 10^{-2}$ & 29 & $1.03 \times 10^{-1}$ & $7.46 \times 10^{-2}$ & 24 & $9.57 \times 10^{-2}$ & $6.73 \times 10^{-2}$ & 32 \\
\hline 80 & $\ldots$ & $\ldots$ & & $1.25 \times 10^{-1}$ & $8.33 \times 10^{-2}$ & 23 & $1.17 \times 10^{-1}$ & $7.01 \times 10^{-2}$ & 25 \\
\hline 90 & $1.37 \times 10^{-1}$ & $8.93 \times 10^{-2}$ & 22 & $2.12 \times 10^{-1}$ & $1.44 \times 10^{-1}$ & 25 & $7.22 \times 10^{-2}$ & $4.40 \times 10^{-2}$ & 36 \\
\hline
\end{tabular}


TABLE VII. Differential cross sections $\left(\times 10^{-16} \mathrm{~cm}^{2} / \mathrm{sr}\right)$ for excitation of the electronic band $\mathrm{V}\left(E_{\mathrm{L}} \sim 9.0-10.2 \mathrm{eV}\right)$ of $\mathrm{pBQ}$.

\begin{tabular}{|c|c|c|c|c|c|c|c|c|c|}
\hline \multirow{2}{*}{$\begin{array}{l}\text { Angle } \\
\text { (deg) }\end{array}$} & \multicolumn{3}{|c|}{$E_{0}=20 \mathrm{eV}$} & \multicolumn{3}{|c|}{$E_{0}=30 \mathrm{eV}$} & \multicolumn{3}{|c|}{$E_{0}=40 \mathrm{eV}$} \\
\hline & Ratio & DCS & Uncert. (\%) & Ratio & DCS & Uncert. (\%) & Ratio & DCS & Uncert. $(\%)$ \\
\hline 10 & $2.74 \times 10^{-2}$ & 1.62 & 69 & $7.48 \times 10^{-3}$ & $4.19 \times 10^{-1}$ & 24 & $1.62 \times 10^{-2}$ & $8.32 \times 10^{-1}$ & 25 \\
\hline 20 & $5.50 \times 10^{-3}$ & $1.00 \times 10^{-1}$ & 68 & $2.52 \times 10^{-2}$ & $3.23 \times 10^{-1}$ & 28 & $1.67 \times 10^{-2}$ & $1.56 \times 10^{-1}$ & 25 \\
\hline 30 & $1.57 \times 10^{-2}$ & $4.61 \times 10^{-2}$ & 29 & $3.57 \times 10^{-2}$ & $6.44 \times 10^{-2}$ & 47 & $5.68 \times 10^{-2}$ & $9.19 \times 10^{-2}$ & 25 \\
\hline 40 & $1.87 \times 10^{-1}$ & $1.87 \times 10^{-1}$ & 23 & $1.16 \times 10^{-1}$ & $1.15 \times 10^{-1}$ & 28 & $6.50 \times 10^{-2}$ & $7.23 \times 10^{-2}$ & 30 \\
\hline 50 & $7.73 \times 10^{-2}$ & $6.28 \times 10^{-2}$ & 27 & $6.24 \times 10^{-2}$ & $5.58 \times 10^{-2}$ & 25 & $4.58 \times 10^{-2}$ & $4.28 \times 10^{-2}$ & 23 \\
\hline 60 & $6.25 \times 10^{-2}$ & $4.66 \times 10^{-2}$ & 23 & $6.69 \times 10^{-2}$ & $5.63 \times 10^{-2}$ & 25 & $5.87 \times 10^{-2}$ & $4.76 \times 10^{-2}$ & 25 \\
\hline 70 & $4.56 \times 10^{-2}$ & $3.19 \times 10^{-2}$ & 28 & $7.14 \times 10^{-2}$ & $5.18 \times 10^{-2}$ & 24 & $6.26 \times 10^{-2}$ & $4.41 \times 10^{-2}$ & 40 \\
\hline 80 & $\ldots$ & $\ldots$ & & $9.60 \times 10^{-2}$ & $6.39 \times 10^{-2}$ & 23 & $9.60 \times 10^{-2}$ & $5.77 \times 10^{-2}$ & 24 \\
\hline 90 & $1.17 \times 10^{-1}$ & $7.64 \times 10^{-2}$ & 22 & $2.26 \times 10^{-1}$ & $1.53 \times 10^{-1}$ & 24 & $5.87 \times 10^{-2}$ & $3.58 \times 10^{-2}$ & 37 \\
\hline
\end{tabular}

this difficult molecular target, the measured data are largely consistent with this theoretical observation.

The experimental differential cross sections obtained for the electron impact excitation of bands IV and $\mathrm{V}$ are presented in Fig. 6 and listed in Tables VI and VII, respectively. Unfortunately, the theoretical calculations are currently restricted to the lower-lying excitation processes, so we have no theoretical results with which we can compare these results. For these two excitation processes, both experimental DCSs display forward-peaked cross sections, reflecting that the excitation processes are dominated by dipole-allowed excitation mechanisms. In this case, the excitation of band IV is dominated by a $\pi \pi^{*}$ excitation, while band $\mathrm{V}$ is dominated by a number of dipole-allowed excitations to Rydberg-like states. ${ }^{16}$

In recent investigations, ${ }^{18,19,24}$ we have tried to evaluate the effect of molecular structure on electron scattering phenomena. As pBQ is structurally similar to benzene and phenol, with all species containing a 6-membered carbon ring, we extend that work here. Here we note that $\mathrm{pBQ}$ is functionally distinct, being a cyclohexadiene, while phenol and benzene are aromatic. In Fig. 7, we compare the excitation process for the $\pi \pi^{*}$ transitions in benzene $\left({ }^{1} \mathrm{E}_{1 \mathrm{u}}, \mathrm{E}_{\mathrm{L}} \sim 7.0 \mathrm{eV}\right),{ }^{60}$ phenol $\left(\mathrm{E}_{\mathrm{L}}\right.$ $\sim 6.3-7.3 \mathrm{eV}$ ), ${ }^{30}$ and $\mathrm{pBQ}$ (band $4, \mathrm{E}_{\mathrm{L}} \sim 7.29-8.30 \mathrm{eV}$ ), where comparable data are available. In each of these species, the $\pi \pi^{*}$ transition relates to promoting a ring $\pi$-bonding electron to an anti-bonding $\pi^{*}$-orbital, within the 6-member carbon ring, so that one might a priori expect these transitions to exhibit qualitatively similar electron scattering characteristics. From Fig. 7, we see that the DCS for each species qualitatively has the same characteristic shape, being forward-peaked at the small scattered electron angles and decreasing in intensity as the scattering angle increases. Interestingly, however, the intensity of the $\mathrm{pBQ}$ cross section for this $\pi \pi^{*}$ transition at the most forward scattering angles is slightly lower than that for the corresponding transitions in both phenol and benzene. This may reflect that the optical oscillator strength (f) for this $\mathrm{pBQ}$ transition, $\mathrm{f}=0.8$, is slightly lower than that for benzene, $\mathrm{f}=0.9$, and phenol with $\mathrm{f}=1.1$. This observation supports the notion that electronic-state excitation processes, relating to a specific molecular feature, may have a characteristic electron scattering differential cross section. Describing the electron scattering behaviour that can be attributed to common structural features, found in many molecules, may therefore be useful in developing empirical approximations that can describe such phenomena from complex and hard to measure molecular systems, when those systems might reasonably be described through those subunits. In this respect, we note that additivity rules have already commonly and quite successfully been employed in describing molecular scattering processes as the sum of the constituent atom scattering cross sections. ${ }^{61}$ We further note that improvements to the additivity rule through screening corrections and interference terms ${ }^{62}$ may, at least in part, capture and describe the molecule's structural information.

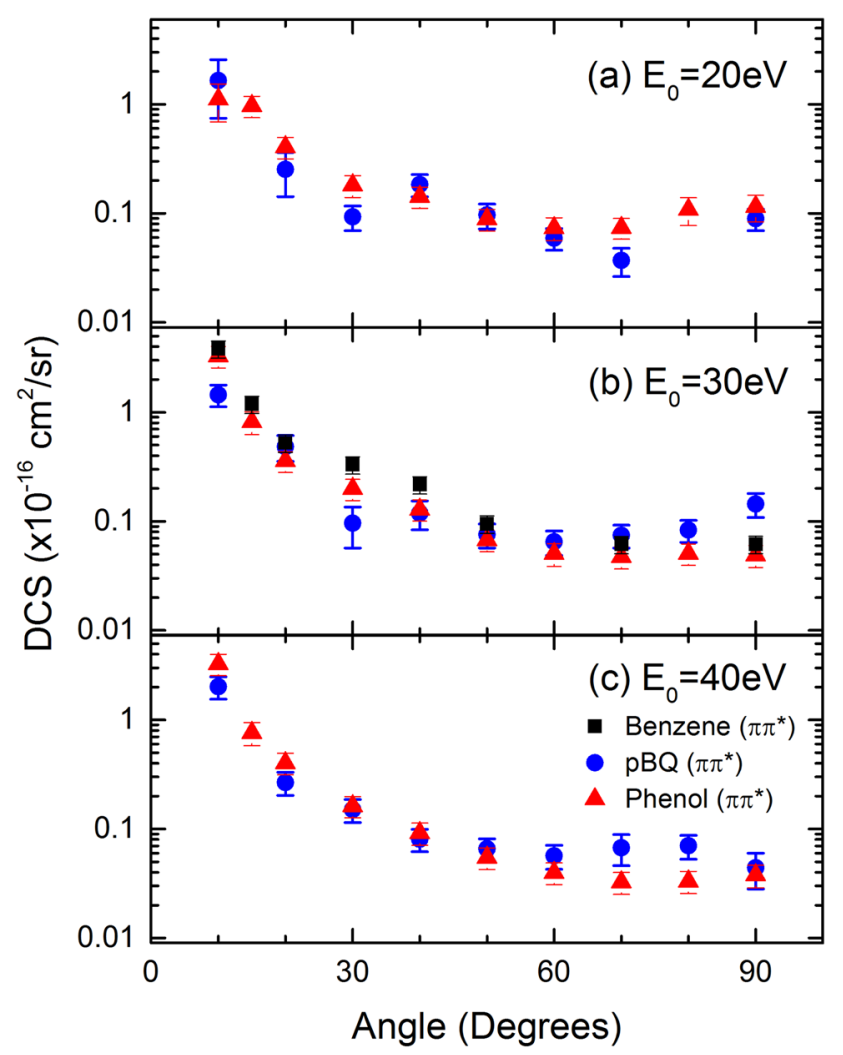

FIG. 7. Experimental differential cross sections for electron impact excitation of composite electronic features for the prominent $\pi \pi^{*}$ transitions in benzene $\left({ }^{1} \mathrm{E}_{1 \mathrm{u}}, E_{\mathrm{L}} \sim 7.0 \mathrm{eV}\right),{ }^{60}$ phenol $\left(E_{\mathrm{L}} \sim 6.3-7.3 \mathrm{eV}\right),{ }^{30}$ and $\mathrm{pBQ}$ $\left(E_{\mathrm{L}} \sim 7.29-8.30 \mathrm{eV}\right)$ : at impact energies of (a) $E_{0}=20 \mathrm{eV}$, (b) $E_{0}=30 \mathrm{eV}$, and (c) $E_{0}=40 \mathrm{eV}$. See the legend in the figure and text for further details. 


\section{CONCLUSIONS}

Differential cross sections for electron impact excitation of six composite electronic bands for para-benzoquinone have been experimentally measured for impact electron energies between 20 and $40 \mathrm{eV}$ and over the $10^{\circ}-90^{\circ}$ range. Where possible, these cross sections were compared to those we calculated using a Schwinger multichannel method with pseudopotentials employing 89-channels (open electronically excited target states) described within a MOB-SCI framework. The theoretical calculations were converged by inclusion of partial waves up to $L_{\max }=13$. Here the theoretical calculations provided the best agreement for a large complicated molecular system to date, although they still typically somewhat overestimated the magnitude of the experimental measurements. This overestimation may reflect that the ionization process is not yet described within the SMCPP framework, such that the excitation cross sections may have gained some of the flux which, in principle, should have flowed into the ionization channels if they were available.

\section{ACKNOWLEDGMENTS}

This work was partially supported by the Australian Research Council (ARC) through Grant No. DP160120787. It was also partially supported by the Spanish Ministry MINECO (Project No. FIS2016-80440), the COST Action (CM301), and ITN-Marie Curie (ARGENT-608163) European Union programmes. M.A.P.L., M.T.d.N.V. (Grant I.D. 305672/20142), R.F.d.C., and M.H.F.B. all acknowledge financial support from CNPq, while F.K.(Grant I.D. 2015/23792-5) also thank FAPESP for financial support. F.F.d.S. acknowledges the Portuguese National Funding Agency FCT-MCTES through a researcher position IF-FCT IF/00380/2014 and together with P.L.-V. the research Grant No. UID/FIS/00068/2013.

${ }^{1}$ B. Huskinson, M. P. Marshak, C. Suh, S. Er, M. R. Gerhardt, C. J. Galvin, X. Chen, A. Aspuru-Guzik, R. G. Gordon, and M. J. Aziz, Nature 505, 195 (2014).

${ }^{2}$ Y. Ding and G. Yu, Angew. Chem., Int. Ed. 55, 4772 (2016).

${ }^{3}$ T. Itoh, Chem. Rev. 95, 2351 (1995).

${ }^{4}$ B. Ómarsson and O. Ingólfsson, Phys. Chem. Chem. Phys. 15, 16758 (2013).

${ }^{5}$ D. Dougherty and S. P. McGlynn, J. Am. Chem. Soc. 99, 3234 (1977).

${ }^{6}$ J. F. Stanton, K. W. Sattelmeyer, J. Gauss, M. Allan, T. Skalicky, and T. Bally, J. Chem. Phys. 115, 1 (2001).

${ }^{7}$ C. R. Brundle, M. B. Robin, and N. A. Kuebler, J. Am. Chem. Soc. 94, 1466 (1972).

${ }^{8}$ L. Åsbrink, G. Bieri, C. Fridh, E. Lindholm, and D. P. Chong, Chem. Phys. 43, 189 (1979).

${ }^{9}$ N. Kishimoto, K. Okamura, and K. Ohno, J. Chem. Phys. 120, 11062 (2004).

${ }^{10}$ K. Piech, T. Bally, T. Ichino, and J. Stanton, Phys. Chem. Chem. Phys. 16, 2011 (2014).

${ }^{11}$ D. B. Jones, E. Ali, C. G. Ning, J. Colgan, O. Ingólfsson, D. H. Madison, and M. J. Brunger, J. Chem. Phys. 145, 164306 (2016).

${ }^{12}$ L. G. Christophorou, J. G. Carter, and A. A. Christodoulides, Chem. Phys. Lett. 3, 237 (1969).

${ }^{13}$ P. M. Collins, L. G. Christophorou, E. L. Chaney, and J. G. Carter, Chem. Phys. Lett. 4, 646 (1970).

${ }^{14}$ C. D. Cooper, W. T. Naff, and R. N. Compton, J. Chem. Phys. 63, 2752 (1975).

${ }^{15}$ A. Loupas and J. Gorfinkiel, Phys. Chem. Chem. Phys. 19, 18252 (2017).

${ }^{16}$ D. B. Jones, P. Limão-Vieira, M. Mendes, N. C. Jones, S. V. Hoffmann, R. F. da Costa, M. T. do N. Varella, M. H. F. Bettega, F. Blanco, G. García,
O. Ingólfsson, M. A. P. Lima, and M. J. Brunger, J. Chem. Phys. 146, 184303 (2017).

${ }^{17}$ T. P. T. Do, H. V. Duque, M. C. A. Lopes, D. A. Konovalov, R. D. White, M. J. Brunger, and D. B. Jones, J. Chem. Phys. 142, 124306 (2015).

${ }^{18}$ D. B. Jones, J. D. Builth-Williams, S. M. Bellm, L. Chiari, H. Chaluvadi, D. H. Madison, C. G. Ning, B. Lohmann, O. Ingólfsson, and M. J. Brunger, Chem. Phys. Lett. 572, 32 (2013).

${ }^{19}$ J. D. Builth-Williams, S. M. Bellm, L. Chiari, P. A. Thorn, D. B. Jones, H. Chaluvadi, D. H. Madison, C. G. Ning, B. Lohmann, G. B. da Silva, and M. J. Brunger, J. Chem. Phys. 139, 034306 (2013).

${ }^{20}$ L. Chiari, H. V. Duque, D. B. Jones, P. A. Thorn, Z. Pettifer, G. B. da Silva, P. Limão-Vieira, D. Duflot, M. J. Hubin-Franskin, J. Delwiche, F. Blanco, G. García, M. C. A. Lopes, K. Ratnavelu, R. D. White, and M. J. Brunger, J. Chem. Phys. 141, 024301 (2014).

${ }^{21}$ H. V. Duque, L. Chiari, D. B. Jones, Z. Pettifer, G. B. da Silva, P. Limão-Vieira, F. Blanco, G. García, R. D. White, M. C. A. Lopes, and M. J. Brunger, J. Chem. Phys. 140, 214306 (2014).

${ }^{22}$ S. M. Bellm, J. D. Builth-Williams, D. B. Jones, H. Chaluvadi, D. H. Madison, C. G. Ning, F. Wang, X. G. Ma, B. Lohmann, and M. J. Brunger, J. Chem. Phys. 136, 244301 (2012).

${ }^{23}$ D. B. Jones, S. M. Bellm, F. Blanco, M. Fuss, G. García, P. Limão-Vieira, and M. J. Brunger, J. Chem. Phys. 137, 074304 (2012).

${ }^{24}$ D. B. Jones, S. M. Bellm, P. Limão-Vieira, and M. J. Brunger, Chem. Phys. Lett. 535, 30 (2012).

${ }^{25}$ D. B. Jones, L. Ellis-Gibbings, G. García, K. L. Nixon, M. C. A. Lopes, and M. J. Brunger, J. Chem. Phys. 143, 094304 (2015).

${ }^{26}$ Z. Masin, J. D. Gorfinkiel, D. B. Jones, S. M. Bellm, and M. J. Brunger, J. Chem. Phys. 136, 144310 (2012).

${ }^{27}$ J. D. Builth-Williams, S. M. Bellm, D. B. Jones, H. Chaluvadi, D. H. Madison, C. G. Ning, B. Lohmann, and M. J. Brunger, J. Chem. Phys. 136, 024304 (2012).

${ }^{28}$ G. B. da Silva, R. F. C. Neves, L. Chiari, D. B. Jones, E. Ali, D. H. Madison, C. G. Ning, K. L. Nixon, M. C. A. Lopes, and M. J. Brunger, J. Chem. Phys. 141, 124307 (2014).

${ }^{29}$ D. B. Jones, G. B. da Silva, R. F. C. Neves, H. V. Duque, L. Chiari, E. M. de Oliveira, M. C. A. Lopes, R. F. da Costa, M. T. do N. Varella, M. H. F. Bettega, M. A. P. Lima, and M. J. Brunger, J. Chem. Phys. 141, 074314 (2014).

${ }^{30}$ R. F. C. Neves, D. B. Jones, M. C. A. Lopes, K. L. Nixon, G. B. da Silva, H. V. Duque, E. M. de Oliveira, R. F. da Costa, M. T. do N. Varella, M. H. F. Bettega, M. A. P. Lima, K. Ratnavelu, G. García, and M. J. Brunger, J. Chem. Phys. 142, 104305 (2015).

${ }^{31}$ R. F. C. Neves, D. B. Jones, M. C. A. Lopes, K. L. Nixon, E. M. de Oliveira, R. F. da Costa, M. T. do N. Varella, M. H. F. Bettega, M. A. P. Lima, G. B. da Silva, and M. J. Brunger, J. Chem. Phys. 142, 194302 (2015).

${ }^{32}$ D. B. Jones, R. F. C. Neves, M. C. A. Lopes, R. F. da Costa, M. T. do N. Varella, M. H. F. Bettega, M. A. P. Lima, G. García, P. Limão-Vieira, and M. J. Brunger, J. Chem. Phys. 144, 124309 (2016).

${ }^{33}$ F. Ferreira da Silva, E. Lange, P. Limão-Vieira, N. C. Jones, S. V. Hoffmann, M.-J. Hubin-Franskin, J. Delwiche, M. J. Brunger, R. F. C. Neves, M. C. A. Lopes, E. M. de Oliveira, R. F. da Costa, M. T. do N. Varella, M. H. F. Bettega, F. Blanco, G. García, M. A. P. Lima, and D. B. Jones, J. Chem. Phys. 143, 144308 (2015).

${ }^{34}$ D. B. Jones, E. Ali, K. L. Nixon, P. Limão-Vieira, M. J. Hubin-Franskin, J. Delwiche, C. G. Ning, J. Colgan, A. J. Murray, D. H. Madison, and M. J. Brunger, J. Chem. Phys. 143, 184310 (2015).

${ }^{35}$ D. B. Jones, R. F. da Costa, M. T. do N. Varella, M. H. F. Bettega, M. A. P. Lima, F. Blanco, G. García, and M. J. Brunger, J. Chem. Phys. 144, 144303 (2016).

${ }^{36}$ D. B. Jones, R. F. C. Neves, M. C. A. Lopes, R. F. da Costa, M. T. do N. Varella, M. H. F. Bettega, M. A. P. Lima, G. García, F. Blanco, and M. J. Brunger, J. Chem. Phys. 143, 224304 (2015).

${ }^{37}$ M. J. Brunger, Int. Rev. Phys. Chem. 36, 333 (2017).

${ }^{38}$ M. J. Brunger, K. Ratnavelu, S. J. Buckman, D. B. Jones, A. Munoz, F. Blanco, and G. García, Eur. Phys. J. D 70, 46 (2016).

${ }^{39}$ M. C. Fuss, L. Ellis-Gibbings, D. B. Jones, M. J. Brunger, F. Blanco, A. Munoz, P. Limão-Vieira, and G. García, J. Appl. Phys. 117, 214701 (2015).

${ }^{40}$ M. J. E. Casey, J. de Urquijo, L. N. Serkovic Loli, D. G. Cocks, G. J. Boyle, D. B. Jones, M. J. Brunger, and R. D. White, J. Chem. Phys. 147, 195103 (2017).

${ }^{41}$ H. V. Duque, T. P. T. Do, M. C. A. Lopes, D. A. Konovalov, R. D. White, M. J. Brunger, and D. B. Jones, J. Chem. Phys. 142, 124307 (2015). 
${ }^{42}$ J. de Urquijo, E. Basurto, A. M. Juárez, K. F. Ness, R. E. Robson, M. J. Brunger, and R. D. White, J. Chem. Phys. 141, 014308 (2014).

${ }^{43}$ T. von Woedtke, S. Reuter, K. Masur, and K.-D. Weltmann, Phys. Rep. 530, 291 (2013).

${ }^{44}$ D. B. Graves, Phys. Plasmas 21, 080901 (2014).

${ }^{45}$ K. Bazaka, M. V. Jacob, and K. Ostrikov, Chem. Rev. 116, 163 (2016).

${ }^{46}$ D. B. Jones and C. L. Raston, RSC Adv. 7, 47111 (2017).

${ }^{47}$ D. B. Jones, X. Chen, A. Sibley, J. S. Quinton, C. J. Shearer, C. T. Gibson, and C. L. Raston, Chem. Commun. 52, 10755 (2016).

${ }^{48}$ M. Benoit, A. Rodrigues, Q. Zhang, E. Fourré, K. De Oliveira Vigier, J.-M. Tatibouët, and F. Jérôme, Angew. Chem., Int. Ed. 50, 8964 (2011).

${ }^{49}$ J. Amorim, C. Oliveira, J. A. Souza-Corrêa, and M. A. Ridenti, Plasma Processes Polym. 10, 670 (2013).

${ }^{50}$ M. A. Ridenti, J. Amorim Filho, M. J. Brunger, R. F. da Costa, M. T. do N. Varella, M. H. F. Bettega, and M. A. P. Lima, Eur. Phys. J. D 70, 161 (2016).

${ }^{51}$ H. Tanaka, M. J. Brunger, L. Campbell, H. Kato, M. Hoshino, and A. R. P. Rau, Rev. Mod. Phys. 88, 025004 (2016).

${ }^{52}$ K. F. Ness, R. E. Robson, M. J. Brunger, and R. D. White, J. Chem. Phys. 136, 024318 (2012).
${ }^{53}$ A. G. Sanz, M. C. Fuss, A. Muñoz, F. Blanco, P. Limão-Vieira, M. J. Brunger, S. J. Buckman, and G. García, Int. J. Radiat. Biol. 88, 71 (2012).

${ }^{54}$ M. J. Brunger and P. J. O. Teubner, Phys. Rev. A 41, 1413 (1990).

${ }^{55}$ M. Allan, J. Phys. B: At., Mol. Opt. Phys. 38, 3655 (2005).

${ }^{56}$ D. B. Jones, F. Blanco, G. García, R. F. da Costa, F. Kossoski, M. T. do N. Varella, M. H. F. Bettega, M. A. P. Lima, R. D. White, and M. J. Brunger, J. Chem. Phys. 147, 244304 (2017).

${ }^{57}$ R. F. da Costa, M. T. do N. Varella, M. H. F. Bettega, and M. A. P. Lima, Eur. Phys. J. D 69, 159 (2015).

${ }^{58}$ R. F. da Costa, F. Kossoski, J. C. R. Costa, M. T. do N. Varella, M. H. F. Bettega, D. B. Jones, M. J. Brunger, and M. A. P. Lima, "An investigation for electronically inelastic electron scattering from para-bezoquinone" (unpublished).

${ }^{59}$ M. Allan, Chem. Phys. 84, 311 (1984).

${ }^{60}$ H. Kato, M. Hoshino, H. Tanaka, P. Limão-Vieira, O. Ingólfsson, L. Campbell, and M. J. Brunger, J. Chem. Phys. 134, 134308 (2011).

${ }^{61}$ L. R. Hargreaves, J. R. Brunton, A. Prajapati, M. Hoshino, F. Blanco, G. García, S. J. Buckman, and M. J. Brunger, J. Phys. B: At., Mol. Opt. Phys. 44, 045207 (2011).

${ }^{62}$ F. Blanco and G. García, Chem. Phys. Lett. 635, 321 (2015). 